\title{
Bringing together knowledge and capabilities: a case study of engineering graduates
}

\author{
Jennifer M. Case and Delia Marshall
}

\begin{abstract}
In contemporary times there is a renewed focus on the purposes of university education in science or engineering, especially in emerging economy contexts like South Africa where the massification of higher education is in its early stages. The contributions by Muller (High Educ 70(3):409-416, 2015) and Walker (High Educ 70(3):417-425,2015) both recognise the crucial importance of expanding epistemological access for students from disadvantaged backgrounds, but their visions offer different emphases on how to proceed. Muller (2015) argues for the centring of disciplinary knowledge, while for Walker (2015) it is the concerns of society that should be central. In this article we argue that both of these are partial answers. We draw on a longitudinal study with ten South African engineering graduates, who were interviewed both in their third year and then approximately a decade later. Our analysis shows how the engagement with disciplinary knowledge is at the heart of the shaping of 'graduateness'. Thus we argue for a coming together of the two perspectives in this issue towards a nuanced perspective on graduateness that recognises the significance of disciplinary knowledge but that also holds a space for the development of student agency in higher education.
\end{abstract}

What should a university degree in science or engineering look like in contemporary times of rapid technological and social change, and especially in a context like South Africa? Muller (2015) and Walker (2015), in the thinkpieces which inspired this response, offer us contrasting-but, we will argue, potentially reconcilable-positions. Both recognise the crucial importance of expanding real epistemological access for students from disadvantaged backgrounds, but their visions offer different emphases on how to proceed.

In this article we argue that both Muller and Walker offer partial answers towards the question which is the departure point for this issue. Drawing on an analysis of empirical data from telephonic interviews conducted with a group of South African engineering graduates, we explore the place of both capabilities and knowledge in graduates' accounts of their personal and professional development. This analysis allows for the development of a position which does not dispute the central significance of knowledge in higher education but also allows for other personal development to be part of the full experience. Significantly, we propose that the engagement with complex and specialised knowledge is a key to the development of 'graduateness'. 
This article, in an exploratory sense then, aims to contribute towards a more nuanced perspective on graduateness that understands the significance of knowledge and discipline but that also holds a space for characterising the development of student agency in higher education, particularly in the domain of science, technology, engineering and mathematics (STEM).

\section{The Muller position}

Muller's article (Muller 2015) draws on an earlier position developed in Young and Muller (2010) in relation to school education. Here, Young and Muller interrogate contemporary movements for progressive educational reform that have arisen from critiques of traditional forms of schooling. Labelling the latter 'Scenario 1' and pointing out the obvious limitations of an educational view that holds knowledge as relatively fixed and educational systems as designed largely around the needs of a small elite, they produce a strident critique of the former ('Scenario 2'), progressive prescriptions for education that derive their direction mainly from an attempt to meet the needs of (a diverse population of) students. While at face value appealing to those with a liberal orientation, Scenario 2, Young and Muller argue, discounts the significance of knowledge itself and thus produces a form of education that is likely only further to entrench the skewed educational outcomes that traditional forms of education produce. In response to these two scenarios, they posit a 'Scenario 3' that aims to retain what is of value in each of these polar positions, and merge them into a hybrid that is relevant to contemporary times. Scenario 3, working from a social realist position, recognises the central significance of knowledge for education, with this recognition of the significance of specialisation and differentiation producing a renewed awareness of the challenges for students that are involved in crossing boundaries when learning new forms of knowledge.

Muller's article moves from the scenarios framework described above towards an examination of the situation in STEM education in a higher education context (Muller 2015). This piece encompasses two key contextual shifts, from an argument about schooling to an argument about higher education, and from an argument about curriculum in general to an argument about STEM in particular. Muller locates his work empirically in a consideration of the South African context, particularly focusing on Academic Development work in STEM. In what follows we provide a preliminary interrogation of Muller's position as articulated "in his 2015 thinkpiece".

Firstly it is important to offer some contextualisation of South African Academic Development (AD) in a broader global context (where it is often termed 'educational development'). Boughey (2007) offers an account of how AD in South Africa emerged from initial (largely pedagogical) efforts concerned with the disadvantaged position of individual black students to become a scholarly-based enterprise at the heart of higher education in South Africa, working centrally in universities to effect the institutional responses that were demanded by the new post-apartheid state. She writes: 'Whereas 
Academic Support had previously been student centred and focused on the perceived deficiencies black students brought with them into higher education, the new critical discourse argued for effort rather to be directed at the curriculum and staff development, which would bring about institutional change' (p. 8). At the level of the discipline, for example in STEM, arguably what this shift meant was a continuation of earlier efforts that focused on student learning, now embedded also in curriculum development work, particularly in the formulation of extended degree programmes. Extended degree (also termed 'foundation') programmes, first launched in the early days of academic support as a response to the needs of students who might be inadequately prepared for university studies, have continued into the present, now explicitly supported through state policy and funding (Kloot et al. 2008).

In his thinkpiece, Muller (2015) expresses a concern that this Academic Development work in STEM might have been seduced by a progressive Scenario 2-type orientation that is centred on 'activity', i.e. a skills focus that downplays knowledge. This appears to us to be something of a straw man and Muller himself notes that 'the case for the constructedness of reality and truth must have been hard to maintain in the face of hardnosed scepticism from the scientists, and an equally hardnosed pragmatism from the engineers'. In fact, it is our contention here that knowledge was never at risk of being devalued in the STEM disciplines, not in the way that Muller and his colleagues have noted its contestation in the humanities (Muller 2000; Young 2008). Thus, pedagogical innovation centred on active student involvement in learning in STEM AD efforts has never been directed towards anything other than the pursuit of disciplinary knowledge, with skills agendas (somewhat favoured by the engineering professions) typically being understood to shore up understanding of the core knowledge. Thus, practical work (in science) and design work (in engineering) have been seen not only as an 'application' of the core disciplinary knowledge, but as a central curriculum element in demonstrating how scientific knowledge is constructed (for example, Buffler et al. 2001).

The scope of this article does not permit more than an illustration of our critique, and here we draw on a 1993 article published in the international journal, Science Education, by Cedric Linder, a key scholar in South African STEM-based Academic Development from the 1980s onwards (Linder 1993). Responding to na ive theories of conceptual change that nonetheless are focused on students' acquisition of recognised scientific knowledge, Linder argues, drawing on empirical data, that conceptual change is not merely the exchange of one (incorrect) conception for the correct one, but it is about a growing sophistication in the recognition of the applicability of a concept to a particular context. For example, the relevance of the wave or the particle model of light depends on the particular context that is under examination, and students need to develop here what Linder terms 'conceptual appreciation'.

What is evident from Linder's work (and which can be noted in the work of other STEM AD scholars, for example, Davidowitz and Rollnick 2011; Potgieter et al. 2005; 
Engelbrecht et al. 2007) is that, firstly, this scholarship is strongly located in the discipline and rests on the evident concerns and positions of the research scientists themselves. This contrasts with the situation portrayed by Muller of AD practitioners adopting a Scenario 2type stance in opposition to mainstream STEM academics' traditionalism. In fact, there is a long history in STEM education, particularly in physics education, of a strong contribution to the field by eminent physicists (for example, Wieman 2007). A second important observation is the location of work such as Linder's within the core of science education research and theorisation. At that time, research on student learning drew on cognitive theories of learning and in the context of the learning of science knowledge, focused particularly on conceptual change. Crucially though, these were not naïve theorisations of knowledge. The very distinctions (knowledge comprising 'know how' and 'know what') that Muller (2014) draws on in another critique of $\mathrm{AD}$ are evident in early science education work of key scholars, most clearly expressed in Richard White's 1998 book 'Learning Science', which outlined clearly the different components of science knowledge at the heart of school science education (White 1988).

In conclusion, it is worth referring to a further statement from this article, where Muller states 'After all, a founding rationale for Academic Development's existence has been that the issue is pedagogical rather than epistemic: that the problem lies with the practices of teaching rather than with the logic of the knowledge or its curricular recontextualisation' (p. 260). We contend that this is a false dichotomy; STEM AD work shows an intense concern with the problems presented by the logic of science knowledge in its curricular recontextualisation. Furthermore, although the major route for addressing this has been in the pedagogical arenanot withstanding some curriculum development in foundation courses-these forms of pedagogical action have never been at the expense of a central focus on knowledge.

\section{The Walker position}

For Walker, the social context in which the university finds itself is a central starting point for thinking about what the STEM degree should entail (Walker 2015). Unlike Muller, whose starting point is in the discipline or profession, for Walker it is the concerns of the world in which it finds itself which should drive the university agenda. From this perspective, the key question for STEM is how science and engineering graduates might use their knowledge, skills and capabilities as professionals to make good lives for themselves, while also contributing to sustainable human development as a public good (Walker and McLean 2013).

In their book, Professional Education, Capabilities and the Public Good, Walker and McLean (2013) use a theoretical framework drawn from the human development and capabilities approach of Amartya Sen (1999, 2009) and Martha Nussbaum (2011) to examine the quality of graduates that professional programmes produce. The capabilities approach requires a consideration of "what people value being and doing, and to work to increase their freedom to be in those ways or to do those things in terms of living lives they regard as good' (Walker 2015). Walker argues that a student or graduate with a wider set of 
capabilities is able to do more with their life, to have more well-being, and by implication, to contribute more towards the public good.

In the context of public-good professional education, Walker suggests it is important that students be given the opportunities to develop and enhance their capabilities through the course of their studies. In order to operationalise what public-good professional education might look like in practice, Walker and McLean (2013) have developed a list of eight core professional capabilities, summarised here in Table 1.

Table 1 Public-good professional capabilities (after Walker and McLean 2013)

\begin{tabular}{ll}
\hline Informed vision & $\begin{array}{c}\text { Understanding the profession in its historical, socioeconomic and } \\
\text { political context nationally and globally } \\
\text { Imagining improved social arrangements }\end{array}$ \\
& Care and respect for, and rapport with, diverse others, especially \\
the poor and vulnerable & Perseverance in difficulty \\
Affiliation (solidarity) & Having a sense of career security \\
Resilience & Community empowerment \\
& Promoting human rights \\
Social and collective struggle & Leading and managing social change \\
& Empathy \\
& Compassion \\
Emotional reflexivity & Personal growth \\
& Acting ethically \\
Being responsible to communities and colleagues & High-level service \\
Integrity & Expressing and asserting own professional priorities \\
& Confidence in the worthwhileness of one's professional work, and \\
to act for change
\end{tabular}

These capabilities, of course, take on different guises in different professional fields. Walker and McLean (2013) have developed six case studies of these capabilities in a range of professional fields in diverse South African universities. In their case study of engineering, it is not surprising that the knowledge and skills capability featured highly. Specialised knowledge is assumed, and attributes of being logical and innovative are valued. Another key capability was resilience, with engineering being viewed as a competitive profession, with technical and practical problems to be overcome. Likewise, students conveyed a strong sense of assurance and confidence in being 'problem-solving agents of change who can make a difference to society' (p. 95), although it was noted that this problem-solving was related more to technical or infrastructure problems than to community or societal problems. Unsurprisingly, the capabilities of informed vision and affiliation were not well developed in the engineering students interviewed, with little real engagement with socio-economic realities. And the capabilities social and collective struggle and emotional reflexivity were not 
touched on in the case study at all.

The capabilities approach also looks at how different individuals can convert available resources into actual functionings, through an examination of so-called conversion factorspersonal, social and environmental (Sen 1999). These conversion factors all make a difference to how an individual converts resources into functioning. As an example of this, Walker (2015) notes that not all students in higher education are equally positioned to convert educational resources into 'actual achievements' or capabilities. Here she notes the potentially desperate experience of university students who come from backgrounds which make university studies a significant challenge. She laments, correctly, the possible downscaling of ambitions and the settling towards instrumental passes and the obtaining of a degree. Higher education does not inevitably increase students' freedom to choose to be and do the things they value, or to live the lives they wished for.

\section{The study}

To interrogate further the two contrasting positions of Muller and Walker, the following research questions underpin the present study:

1. Drawing on Walker's definition of capabilities, what do graduates value being and doing?

2. Responding to Muller concerns, what role does knowledge play in graduates' accounts, and how does this relate to the capabilities?

The empirical data for this study come from a larger study which recruited participants from a third year engineering class, interviewed them closely about their experiences at that time, then tracked them down nearly 10 years later and conducted a telephonic interview at that point (Case 2013). For the purposes of the present analysis we focus mainly on the latter interview with the graduates now in the workplace. We also work with a smaller subset of the class for this analysis: focusing on the 10 students (out of a larger group of 35) who entered the programme through the extended degree option which was explicitly designed for students from disadvantaged backgrounds. In considering the formation of graduateness, in this analytical choice we argue that the findings from this group-who undoubtedly had the toughest route from home and school life to graduation-offer an important perspective. Here we follow a group for whom graduating had the most significant possibility for impacting on their life chances.

Drawing on the earlier interviews, we can develop the following background characterisations for this group. All of them are black ${ }^{1}$ South Africans; at that point the engineering extended degree programme had a majority of black African students and only a small group of coloured students. Most of the students had grown up either in a township or in a rural area. They were mostly raised by either a single parent or a grandparent. Their

${ }^{1}$ Note that in using racial terminology we are not ascribing any biological significance to this descriptor, but rather noting that in the 
schooling was either in a state school (in one of those historically designated for black students) or in a low-cost private school. Here we note the imprint of the apartheid legacy on the home and schooling lives of young black South Africans, particularly given that these students were already teenagers at the time of the transition to democracy.

They all started university in the late 1990s, entering the chemical engineering programme at the University of Cape Town. The experience of being a student in this programme has been well documented in the larger study (Case 2013), and they all shared the experience of academic difficulty and challenge. Their patterns of success in the programme spanned a fairly wide range, with a small minority graduating in the regulation 5 years, and others taking up to 8 years, shown below in Table $2 .^{2}$ It needs to be noted that with this group having been recruited in a third year course, the study was not able to capture the experiences of a significant group of students who do not get to this point in the programme.

None of these students had family resources for funding university studies and many of them had industrial bursaries. Those who did not hold industrial bursaries or who lost them along the way due to poor academic performance were able to receive financial support through the university.

All of the participants started to work on graduation and all have been in continuous work since then, although some have changed employers at various points in their careers. At the time of the interview all graduates were between 5 and 10 years in the work place. Some are in positions close to production operations and others have moved into project work or head office work, with their job designations as shown in Table 2. Here it can also be noted that the majority of them are in work related to mining and minerals processing, currently a significant employer of chemical engineers in South Africa.

As noted above, the present analysis drew predominantly on the telephonic interviews that were conducted with graduates some $5^{-10}$ years after graduation. The interview followed a semi-structured format, with the following basic outline of questions:

1. What have you been doing since graduation? Update me on your career trajectory and what you are currently doing.

2. Looking back on your undergraduate experience from this perspective, how does it appear?

3. What knowledge from your degree have you used in your work?

4. [Following a descriptor of key changes to be implemented in a new curriculum, including an increased focus on sustainable development] Give me your opinion on the proposed new curriculum.

\footnotetext{
${ }^{2}$ The names given here are all pseudonyms.
} 
At this point it is important to note the limitations of these data. A fairly open-ended interview protocol made it more likely to capture the fine-grained narrative data that we were looking for, but also brings into the analysis the fact that different people have different degrees of comfort with expressing themselves in this format, especially over the telephone.

Table 2 Participants in the study

\begin{tabular}{|c|c|c|c|c|}
\hline & $\begin{array}{l}\text { Number } \\
\text { of years to } \\
\text { graduation }\end{array}$ & Current position & $\begin{array}{l}\text { Sector in which } \\
\text { employed }\end{array}$ & $\begin{array}{l}\text { Still } \\
\text { with } \\
\text { bursary } \\
\text { company }\end{array}$ \\
\hline Mcebisi & 7 & $\begin{array}{l}\text { Operations manager (commissioning new } \\
\text { plants) }\end{array}$ & $\begin{array}{l}\text { Mining and minerals } \\
\text { processing }\end{array}$ & \\
\hline Mpho & 8 & $\begin{array}{l}\text { Process engineer (working on software } \\
\text { projects) }\end{array}$ & Chemical industry & \\
\hline Nkosazana & 5 & $\begin{array}{l}\text { Executive technical assistant to CEO (Head } \\
\text { Office position) }\end{array}$ & $\begin{array}{l}\text { Mining and minerals } \\
\text { processing }\end{array}$ & $\mathrm{X}$ \\
\hline Nkosi & 5 & $\begin{array}{l}\text { Operational energy manager (working on } \\
\text { projects) }\end{array}$ & Petrochemicals & $\mathrm{X}$ \\
\hline Phumzile & 6 & $\begin{array}{l}\text { Refinery asset manager (Head Office } \\
\text { position) }\end{array}$ & Petrochemicals & \\
\hline Sibongile & 5 & Plant manager (day to day operations) & $\begin{array}{l}\text { Mining and minerals } \\
\text { processing }\end{array}$ & \\
\hline Sipho & 8 & Metallurgist (day to day operations) & $\begin{array}{l}\text { Mining and minerals } \\
\text { processing }\end{array}$ & \\
\hline Sizwe & 6 & Plant section head (day to day operations) & $\begin{array}{l}\text { Mining and minerals } \\
\text { processing }\end{array}$ & $\mathrm{X}$ \\
\hline Tshepo & 6 & Process engineer (working on projects) & $\begin{array}{l}\text { Mining and minerals } \\
\text { processing }\end{array}$ & \\
\hline Zanele & 5 & Metallurgist (day to day operations) & $\begin{array}{l}\text { Mining and minerals } \\
\text { processing }\end{array}$ & $\mathrm{X}$ \\
\hline
\end{tabular}

To minimise some of this discomfort the interviews were deliberately not recorded, but rather typed up live by the interviewer, and these notes sent back immediately to the interviewee for their consideration. The interviews took place at prescheduled times, usually during work hours, and it was also a possibility that the person might have been anxious about getting back to a work task (or even been a bit distracted during the interview). The quality of data obtained does not suggest that these were significant problems, but it is noted that some participants were particularly lengthy especially in describing their jobs or looking back on their undergraduate experiences, while others were fairly brief. Analytically therefore it is important not to read too much into presences and absences. The data are better taken as a collective whole representing aspects of graduateness, rather than analysing what one person did say and another person did not (choose to) say in the interview. 


\section{Findings}

As noted above, the analysis followed the research questions which emerged from a juxtaposition of the visions offered by Walker (2015) and Muller (2015) thinkpieces which we are responding to in this issue. We start with the first research question, which aims to characterise graduates' well-being in the terms of the definition originally offered by Sen ('what people value being and doing') and taken up by Walker in her framing of graduate capabilities (Walker 2015). Rather than working off Walker and McLean's (2013) list, as a departure point we adopted a relatively grounded approach, working with an overall focus on capabilities. This yielded three themes, presented below.

\section{Capabilities}

\section{Being an engineer}

All ten participants in this study offered a clear account of their career trajectory after graduation up until their present job. We noted amongst the participants two students who gave an exceptionally detailed account of their technical skills, their ownership of the problems that they had had to solve over time, and the way that they had solved these. Both Nkosi and Sizwe, who had been working since graduation for the same company that had funded their studies, gave detailed accounts of the different positions and responsibilities that they had held over this period. For example, Nkosi described a period in his career where he had been working on a new plant:

Also there were some safety concerns ... so I designed a system that would indicate if there was a leak. And also I was involved with the commissioning and startup of the plant, which included shift work to monitor the plant on a 24 hour basis. And also to check that the system was working according to the design intent. Also to check the mass and energy balances around the system. I also did a lot of small modifications on that plant.

Another group of students gave a little less technical detail on their work but nonetheless demonstrated striking ownership and agency in their work. For example, Zanele said:

They give you a plant, they say this is your plant, you must optimise it. If it's not performing, they all ask you what's wrong. To be honest, when they say 'this is your plant', ... it's wow. It's something I have been missing for all my life!

Thabiso spoke of enjoying supporting a unit for which she had responsibility, Mcebisi had had to run new plants after commissioning and Mpho spoke of the responsibility for keeping a production line running and needing to make plans quickly if the line went down.

Simangele focused her account more on the people side of managing a plant; the need to keep a team together. Two other participants, Tshepo and Sipho, were less explicit in articulating ownership and agency, but nonetheless spoke to their roles and how these fitted into the larger operations of the company. 
One graduate, Nkosazana, having been identified as having high potential within a large corporation, had been selected for a series of graduate training opportunities and was currently acting as assistant to the CEO. She voiced a slight lament that this career track had meant that she was not sure that she had yet added sufficient value to the company, compared to what had been invested in her to date. Even her voicing a sense of what she wanted to be adding indicates that for this group there is a clear personal expectation that one wants to be in a position of owning responsibility and having the space to make and execute decisions.

Here we have shown that all of these participants articulate to some degree an inhabiting of their roles as engineers, an owning of the responsibilities that go with this role, and a sense of agency in being able to use their technical knowledge. This first theme thus confirms the basic findings of Walker and McLean's (2013) study on engineers discussed above; the three interlocking capabilities of knowledge and skills, resilience, and assurance and confidence, are captured in these depictions of 'being an engineer'.

\section{Locating career choices in bigger life decisions}

With regard to Walker's (2015) definition of capabilities as being that which people value being and doing, the analysis moved to consider interviewees' responses to the first interview question which asked participants to describe their career trajectories. Here it was notable that many of them related their career decisions to larger decisions about their life.

Some participants mentioned having made decisions or company changes based on their family configurations and the geographical location of their spouse's work. Both Mcebisi and Sipho had changed jobs in order to be closer to where their wife worked.

Sipho had also had to take his health into account when a particular job location with significant amounts of dust and sulphur dioxide had impacted on his respiratory health. He had been forced to change companies at this point.

Another consideration for some participants had been getting the kind of work experience that they valued. Sizwe had deliberately sought out a posting in a small town since he knew he was likely to more quickly get to positions of responsibility in that context.

Nkosi had resigned from his bursary company some years after commencing work, yet returned quite quickly when he found the culture of this other company too relaxed:

So I didn't stay there for long, because the culture there, they were so relaxed, so I thought this was going to kill my career, because I was used to working under pressure.

Coming back to his original job had also allowed Nkosi to pursue part-time lecturing at the 
local campus of a university of technology. He really enjoyed doing this and was particularly proud that, due to his efforts, the pass rate of a core chemical engineering course had improved.

Looking forward, a number of the graduates also voiced aspirations for the future that did not necessarily involve mainstream engineering work. Sibongile, currently in a plant manager role, said that she did not envisage doing this forever. She indicated that she would like to do an MBA and run her own business one day. Sizwe, who as a third year student had already indicated an extraordinary level of social commitment (Marshall and Case 2010), as an engineer had found a way to be centrally involved in the training of students doing vacation work at the company and in his personal life, was also involved in doing community work with young people. Long term he voiced a desire to start his own ministry with young people. Mcebisi, currently in operations, similarly to Sibongile did not see himself managing these kind of hours in the long run and reckoned that in due course he would want to change direction. He mentioned a possible career move towards consulting work alongside some school teaching.

This theme has shown that 'being an engineer' is located in a larger sense of personal purpose. Interviewees here gave detailed evidence of how their career decisions were located in larger questions of what they valued in life.

\section{Locating engineering within the broader societal/environmental context}

Walker (2015) sees capabilities within a larger context of societal challenges, and thus a final step in this analysis was to look at evidence for interviewees locating engineering work within its social context. Here, the interview question which asked for their view on proposed curriculum reforms which included a greater emphasis on sustainable development provided useful data. Most graduates offered their perspective on engineering and the environment. Some responses were relatively limited to regulatory issues focusing on compliance and the company reputation. For example, Nkosazana said:

Working for a mining company, that has a lot to do with reputational issues ... for waste disposal, cleaner processes, that is what the world is moving towards.

Many of the graduates, however, saw environmental issues as quite central to their engineering work, particularly focusing on issues around waste, energy and water. For example, in response to the question of whether issues around sustainable development featured in his daily work, Mcebisi said:

It's there, definitely. We are with that, every time. The industry I am doing now, they require a lot of that. We have to use minimum energy. All the water is in circulation. For cleaner stuff - clean energy - mining guys don't do a lot of that. Now we are designing our plants at minimum power draws. I think the plant I am on, it's $1.8 \mathrm{MW}$, compared to other mines, its less than $10 \%$ than the other guys on the older plants. 
A few graduates pointed to the broader global context of debates and developments around sustainable development. For example, Sibongile said:

Look, it cannot not be pertinent. I think the whole - sustainable development - is the future. I don't think the world has got an option. So it's something we deal with, it's just that currently it hasn't taken off, China and the US are dragging their feet about Coming back to his original job had also allowed Nkosi to pursue part-time lecturing at the local campus of a university of technology. He really enjoyed doing this and was particularly proud that, due to his efforts, the pass rate of a core chemical engineering course had improved.

Looking forward, a number of the graduates also voiced aspirations for the future that did not necessarily involve mainstream engineering work. Sibongile, currently in a plant manager role, said that she did not envisage doing this forever. She indicated that she would like to do an MBA and run her own business one day. Sizwe, who as a third year student had already indicated an extraordinary level of social commitment (Marshall and Case 2010), as an engineer had found a way to be centrally involved in the training of students doing vacation work at the company and in his personal life, was also involved in doing community work with young people. Long term he voiced a desire to start his own ministry with young people. Mcebisi, currently in operations, similarly to Sibongile did not see himself managing these kind of hours in the long run and reckoned that in due course he would want to change direction. He mentioned a possible career move towards consulting work alongside some school teaching.

This theme has shown that 'being an engineer' is located in a larger sense of personal purpose. Interviewees here gave detailed evidence of how their career decisions were located in larger questions of what they valued in life.

One of the graduates explicitly reflected also on the social impact of engineering. Mcebisi, comparing his professional world to that of his medical doctor wife, said the following:

Medicine has more social contact. For us, when you graduate you go to a mine. They get you a nice office. You don't even know the challenges of the guy underground. Then you are sorted. You don't know the challenges out there.

Thus we see nascent evidence on how contemporary engineering graduates are reconciling their professional career with their grasp of contemporary environmental and social challenges.

\section{Knowledge}

As noted earlier, during the telephonic interview, graduates were invited to reflect back on their undergraduate studies, with the interviewer prompting graduates to consider both what course knowledge they had applied in their work and also the broader experience of 
being a chemical engineering student. The responses to this interview question thus provided a useful departure point for a consideration of the role of knowledge in the formation of graduateness.

With regard to using actual technical knowledge obtained in courses, some graduates did indicate that a few courses had had direction application in the workplace. Most students, when asked, pointed to the second year core course on material and energy balances, which was an approach they continued to use across their work. Furthermore, Tshepo pointed to third year courses where he had learnt the fundamentals of engineering modelling. Nkosazana pointed to the final year professional communications course which taught report writing.

However, contrary to what might be expected, this discussion on the usefulness of technical knowledge from the undergraduate degree was relatively limited. What featured more prominently in reflections on the undergraduate degree was commentary on the way in which the engagement with knowledge had promoted the formation of particular dispositions.

Firstly, many graduates pointed to having developed confidence to tackle challenges through succeeding in the difficult intellectual demands that the undergraduate degree had posed. Sibongile stated explicitly:

But, it gives you the confidence. Because I did well in the degree, when I got to work, I knew I would do well.

This confidence, of course, is at least partly related to being able to work in a particular manner. Some graduates described it in terms of the engineering approach to problemsolving. Nkosi said:

If I look back, the aim was to teach us how to think. That is very important now at work. To be able to take a very complex problem and simplify it, make assumptions. I think you guys helped us a lot with that skill.

Nkosazana said:

Chem Eng has shaped my way of thinking - you are taught to think systematically. It's more important sometimes than the actual technical knowledge.

Another focus was around being able to work independently and responsibly, to be able to take ownership for a problem. Mcebisi, describing what he learnt in the degree, added:

And to work under pressure! That definitely. You can give me anything at any time, I can handle it. I don't flinch. I just say 'bring it', I have been through hell before. 
A further aspect mentioned was the ability to learn new knowledge, to be able to work with resources and to ask for help if needed. Phumzile, who had had to repeat her third year of studies, said the following:

For me actually it was a learning curve. ... Previously I was shy to ask questions. I would read for hours at hand but I couldn't tell you what I had read. But after that whole episode, it was a close call, being given a chance to come back, I had a relook at the way I was studying. Looking back at the concepts, to see where I was going wrong. I now know how to learn and how to ask. It's not just reading a book.

Poignantly, students who had had to repeat courses all spoke of these experiences ultimately as significant times of personal growth. For example, Tshepo, said:

For me, repeating courses, disappointing as it was, it helped shape the person that I am.

Mpho said:

I think I wouldn't have been where I am if some things didn't go wrong in my life.

Two graduates explicitly mentioned the support they had received from the university during these difficult experiences. Phumzile remembered chatting to the interviewer at this time and felt it had really helped to have a dedicated person who students could approach. Sipho spoke in detail about a range of resources where he had found support when he needed it. Firstly, he felt that the extended degree programme had really helped in the transition. He also remembered the year when his father had passed away and he nearly failed all his courses. The university had readmitted him on condition he obtain help from a psychologist and looking back he was really grateful for this: 'it helped me resurrect my spirit'. Finally, he had been given an opportunity to resubmit his final year design project during the holiday and had managed to pass on this second attempt.

Most of the graduates in this study had started their university studies with the support of an industrially sponsored bursary. Such bursaries typically require students to do vacation work in the company and to work for the company after graduation for a fixed number of years. As noted above, four of the graduates were still working for their bursary company. For some of them, however, early academic failure had meant that they had lost this support at some point in their studies and had to find financial support elsewhere. Graduates who had not had the experience of vacation work were seen to comment in the interview that they felt this had been to their disadvantage. For example, Phumzile said:

I think sometimes the way the concepts were taught, ... it was a lot of theory but not clear why we were learning something. ... You saw that a lot of people who had bursaries or vac work - they could see when they came back what things referred to. For a person who didn't have vac work, you couldn't see the objective of the course. There was a big gap between 
what we studied and when we started working.

This is an example of how students can be differently positioned to convert educational resources (in this case a theoretical course) into actual functioning (a capability to link with engineering practice). Here, students with bursaries and hence with access to vacation work were advantaged.

The analysis directed towards the knowledge question thus paints an interesting picture. Knowledge was part of the identity noted in the analysis of capabilities, and here we see further detail on what that means. Graduates did note the use of some of the knowledge acquired in the engineering programme, but felt that much more important was the way this engagement with knowledge had shaped their being.

\section{Discussion and conclusion}

The research questions guiding this study were framed by the competing visions of STEM education presented by Walker (2015) and Muller (2015) which are being responded to in this special issue. The first question draws on Walker's (2015) definition of capabilities and, with regard to the accounts given by the interviewees, seeks to identify what graduates value being and doing. Although different participants gave different degrees of detail in describing their careers, there was a clear sense across all accounts that they valued their roles as engineers and that they took pride in using their knowledge and skills to solve engineering problems. The sense of ownership of a role and personal agency to effect change was strongly evident in the data; in short, these graduates really value being engineers and doing engineering work. The data also gave clear evidence of how graduates fitted their career choices into the context of significant life decisions involving partners, family, health and other interests. Finally, in response to an interview question that had prompted some reflection on issues of sustainable development and engineering, most graduates were able to engage with these issues at some level.

With regard to Sen's departure point in outlining a capabilities approach, which is to focus concern on people's ability to be 'living lives they regard as good' (Walker 2015, p. 420), this study provides a close-up picture of what this means for a group of South African engineering graduates. They are confident in what they do and they are people who are well on the way in making the lives that they want to lead. Their specialised professional status means that they are highly employable and thus have choices they can make. Within their companies they are starting to be recognised for their expertise and are being promoted to positions of responsibility.

Comparing these findings to Walker and McLean's (2013) findings regarding the specific capabilities displayed by senior engineering students, there is a large degree of correspondence with our results. With regard to the three key capabilities that were found in the original study, we confirm that knowledge and skills are paramount capabilities for engineers and that these also link to an attitude of assurance and confidence. Resilience 
also features strongly in their accounts; in this study we show in detail how this resilience starts to develop during the grappling with challenging knowledge in the undergraduate degree. This becomes a key disposition that is needed in the challenging workplace when novel problems present with regularity. We also find that issues around impact of engineering on the broader societal context are perhaps less developed in graduates' spontaneous accounts of their work (similar to Walker and McLean's finding that capabilities of informed vision and affiliation were less developed), although when prompted many of them were able to engage at this level. They are all employed as engineers in companies and corporations. Their focus, not surprisingly, is a lot on the operations and priorities of the company. However, the emerging views on social responsiveness and future career directions, as expressed by Sizwe and Mcebisi, suggest that as these graduates move on in their careers we might expect these aspects to become more prominent. This is in line with the recent findings of the sociologist Margaret Archer (2007), who notes that meta-reflexivity, where the individual is less concerned about their own success and starts to define their life's interests more significantly in terms of others, is something that usually grows as the person grows older and moves to a different stage in their life.

With regard to the curriculum that these students had been through, the graduates in this study had completed a final year course entitled 'Business, Society and the Environment', somewhat similar to the senior course that the engineering students in Walker and McLeans's (2013) study had completed. Here it is interesting to note that a subsequent curriculum reform in this programme has noted the limitations of the traditional one-off course in sustainable development and has developed a much more integrated approach which sees these ideas woven through the programme from first year (von Blottnitz et al. 2015).

These findings add further support to a well-established view on the distinctive roles that professionals play in society (Young and Muller 2014; Sullivan 2004). A new challenge arises in conceptualising what 'public-good professionalism' (Walker and McLean 2013) will mean in a specific professional context, particularly recognising that in dynamic and challenging times, professional roles and responses might need to change. Thus, while the role of an engineer might historically have been thought of as confined to technical problems, a contemporary understanding of engineering recognises that engineering work needs to be highly responsive to its social and environmental context (Grasso and Burkins 2009).

The second research question guiding the present study responds to the concerns raised by Muller (2015) by asking of these interview accounts, where does the knowledge come in? Moreover, in accounting for knowledge, how does this relate to the capabilities identified?

In looking for the role of knowledge in these accounts, it is not so much the specific technical knowledge learnt in particular courses and applied in particular career challenges 
that is significant, but rather the broader ways in which graduates felt they had a particular 'way of knowing'. This disposition towards knowledge involved confidence to tackle problems, thinking systematically, working independently and responsibly and being able to learn new knowledge. The role of knowledge in these professionals' lives is thus much more than the simple application of a body of knowledge; it is the formation of a whole person who engages with the world and with knowledge in particular way. Crucially, many graduates were able to articulate how their struggles with knowledge in the undergraduate curriculum had been central to this formation of character.

Some of these graduates had experienced failure of courses and the consequence of falling behind a year in their undergraduate studies. Compared to Walker's (2015) perspective which focuses on the possibility of this being an ultimately alienating experience, these accounts (albeit of students who did ultimately graduate) suggest that failure, in a context where the environment is supportive of the student, can contribute to personal development.

Drawing together the findings of this study across both research questions, we obtain a distinct picture of the relationship between knowledge and agency in the formation of the graduate professional. These graduates signal their capabilities predominantly in terms of knowledge and skills needed to be an engineer, but also point to the ways in which a challenging undergraduate degree formed them in particular ways. In conclusion then, this study points to a synthesis of the positions articulated by Muller (2015) and Walker (2015) - knowledge matters, but so does the development of individual capabilities, and it is the engagement with knowledge that is central to the development of capabilities in the graduate professional. 


\section{References}

Archer, M. S. (2007). Making our way through the world: Human reflexivity and social mobility. Cambridge: Cambridge University Press.

Boughey, C. (2007). Educational development in South Africa: From social reproduction to capitalist expansion? Higher Education Policy, 20, 5-18.

Buffler, A., Allie, S., \& Lubben, F. (2001). The development of first year physics students' ideas about measurement in terms of point and set paradigms. International Journal of Science Education, 23(11), 1137-1156.

Case, J. M. (2013). Researching student learning in higher education: A social realist approach. London: Routledge.

Davidowitz, B., \& Rollnick, M. (2011). What lies at the heart of good undergraduate teaching? A case study in organic chemistry. Chemistry Education Research and Practice, 12(3), 355-366.

Engelbrecht, J., Harding, A., \& Preez, J. D. (2007). Long-term retention of basic mathematical knowledge and skills with engineering students. European Journal of Engineering Education, 32(6), 735-744.

Grasso, D., \& Burkins, M. D. (Eds.). (2009). Holistic engineering education: beyond technology. New York: Springer.

Kloot, B., Case, J. M., \& Marshall, D. (2008). A critical review of the educational philosophies underpinning Science and Engineering foundation programmes. South African Journal of Higher Education, 22(4), 799-816.

Linder, C. J. (1993). A challenge to conceptual change. Science Education, 77(3), 293-300.

Marshall, D., \& Case, J. M. (2010). Rethinking 'disadvantage' in higher education: A paradigmatic case study using narrative analysis. Studies in Higher Education, 35(5), 491-504.

Muller, J. (2000). Reclaiming knowledge: Social theory, curriculum, and education policy. London: RoutledgeFalmer.

Muller, J. (2014). Every picture tells a story: Epistemological access and knowledge. Education as Change, 18(2), 255-269.

Muller, J. (2015). The future of knowledge and skills in science and technology higher education. Higher Education, 70(3), 409-416.

Nussbaum, M. C. (2011). Creating capabilities: The human development approach. Cambridge: Belknap Press. Potgieter, M., Rogan, J. M., \& Howie, S. (2005). Chemical concepts inventory of grade 12 learners and UP foundation year students. African Journal of Research in Mathematics, Science and Technology Education, 9(2), 121-134.

Sen, A. K. (1999). Development as freedom. Oxford: Oxford University Press.

Sen, A. K. (2009). The idea of justice. Cambridge, MA: Harvard University Press.

Sullivan, W. M. (2004). Work and integrity: The crisis and promise of professionalism in America (2nd ed.). San Francisco: Jossey-Bass.

von Blottnitz, H., Case, J. M., \& Fraser, D. M. (2015). Sustainable development at the core of undergraduate engineering curriculum reform: A new introductory course in chemical engineering. Journal of Cleaner Production, 106, 300-307.

Walker, M. (2015). Imagining STEM higher education futures: Advancing human well- 
being. Higher Education, 70(3), 417-425.

Walker, M., \& McLean, M. (2013). Professional education, capabilities and the public good: The role of universities in promoting human development. London: Routledge.

White, R. T. (1988). Learning science. Oxford: Blackwell.

Wieman, C. E. (2007). Why not try a scientific approach to science education? Change, 39(5), 9-15. Young, M. (2008). Bringing knowledge back in: From social constructivism to social realism in the sociology of education. London: RoutledgeFalmer.

Young, M., \& Muller, J. (2010). Three educational scenarios for the future: Lessons from the sociology of knowledge. European Journal of Education, 45(1), 11-27.

Young, M., \& Muller, J. (2014). Knowledge, expertise and the professions. London: Routledge. 